\title{
A study of correlation of antenatal uterine scar thickness by transabdominal ultrasound with intraoperative lower uterine segment scar grading in elective repeat cesarean delivery
}

\author{
Haripriya Vedantham, Nandini Joshi Nee Jahagirdar*, Ramadevi N., \\ Vasundhara Kamineni, Sarada Saranu
}

Department of Obstetrics and Gynecology, Kamineni Academy of Medical Sciences and Research Center, L. B. Nagar, Hyderabad, India

Received: 15 October 2019

Accepted: 15 November 2019

\section{*Correspondence:}

Dr. Nandini Joshi nee Jahagirdar,

E-mail: jahagirdar.nandini@gmail.com

Copyright: () the author(s), publisher and licensee Medip Academy. This is an open-access article distributed under the terms of the Creative Commons Attribution Non-Commercial License, which permits unrestricted non-commercial use, distribution, and reproduction in any medium, provided the original work is properly cited.

\begin{abstract}
Background: Caesarean section (CS) is the most common obstetric surgery performed world-wide. The objective of this study was to correlate the antenatal sonographic lower uterine segment (LUS) scar thickness in women with previous one cesarean section with intra operative LUS scar grading.

Methods: A Prospective observational study was conducted from December 2014 to November 2015. In a tertiary care center. 200 pregnant women from ANC clinic with previous one LSCS were recruited. Transabdominal USG done between 36-38 weeks. LUS thickness was measured from bladder wall-myometrium interphase and myometrium-chorioamniotic membrane inter phase. Intraoperative grading of LUS scar was done. Based on grading of scar participants were assigned into scar dehiscence group (grade III and IV LUS scar) and non-dehiscence group (Grade I and II LUS scar).

Results: Mean LUS thickness was 3.41 $\pm 0.623 \mathrm{~mm}$ (range: $2-7 \mathrm{~mm}$ ). Mean LUS thickness in the scar dehiscence group and non-dehiscence group was $2.98 \pm 0.55 \mathrm{~mm}$ and $3.48 \pm 0.60 \mathrm{~mm}$ (P value < 0.05 ) respectively. A cut off value of $3.5 \mathrm{~mm}$ was derived from ROC with sensitivity, specificity, positive and negative predictive value of $92.6 \%$, $54.3 \%, 24.0 \%, 97.8 \%$, respectively. The present study reported 27 (13.5\%) cases of scar dehiscence.

Conclusions: Ultra-sonographic evaluation of LUS thickness correlated significantly with intraoperative LUS appearance. USG evaluation of LUS can be used as a screening test to predict the LUS scar integrity. Risk of dehiscence is increased in women with thin LUS i.e. sonographic LUS thickness of $<3.5 \mathrm{~mm}$ and needs to be further evaluated. Women with previous one LSCS with thick LUS i.e. sonographic LUS thickness of > $3.5 \mathrm{~mm}$, can be counselled regarding TOLAC if not contraindicated.
\end{abstract}

Keywords: Elective repeat caesarean delivery, Grades of scar, Lower uterine segment measurement, Scar dehiscence, Scar thickness, Trial of labor after caesarean

\section{INTRODUCTION}

Caesarean section (CS) is the most common obstetric surgery performed world-wide. The rate of CS is increasing over time and its rate varies internationally from $10-25 \% .{ }^{1}$ World Health Organization stated: "There is no justification for any reason to have CS rates higher than 10-15\%". WHO issued a new statement in 2015 with the headline "Every effort should be made to provide caesarean sections to women in need, rather than striving to achieve a specific rate". ${ }^{2}$ WHO estimate of caesarean rate for India is $8.5 \%$, repeat caesarean section being the commonest indication. ${ }^{3-5}$ It has been shown that the rate 
of uterine rupture is only marginally increased among women undergoing a trial of labour6 compared to those undergoing an elective repeat caesarean section $(0.4 \%$ versus $0.2 \%$ OR $=2.1)$, with a significant decrease in need for transfusion $(\mathrm{OR}=0.57)$ or hysterectomy $(\mathrm{OR}=$ 0.39). This has led to vaginal births after caesarean being encouraged. However, nearly a quarter of women, who are candidates for a trial of labour require induction of labour. ${ }^{7}$ Zelop $\mathrm{CM}$ et al, and several others have concluded that among women with a previously scarred uterus, induction of labour is associated with an increased risk of uterine rupture compared with spontaneous labour $(2.3 \% \text { versus } 0.7 \% \mathrm{p}=0.001)^{8}$

In order to assess the risk of uterine rupture better, sonographic measurement of lower uterine segment thickness near term has been proposed, assuming that there is an inverse correlation between LUS thickness and the risk of uterine scar defect. ${ }^{9,10}$ Antenatal sonographic assessment of lower uterine segment may therefore increase safety for women undergoing a trial of labour by selecting women with lower risk of uterine rupture.

While a large prospective study demonstrated that a full LUS thickness greater than $3.5 \mathrm{~mm}$ had a strong negative predictive value, the best cut-off values and the best measuring technique remain controversial. ${ }^{11,12}$

\section{METHODS}

The present study was conducted in the department of Obstetrics and Gynaecology of a tertiary care centre during a one-year period from December 2014 to November 2015. Institutional review board approval and ethical committee clearance was taken. An informed and written consent was taken from all the participants in the study.

Prospective observational study conducted with 200 eligible and consenting pregnant women with previous LSCS who were registered for antenatal care during the study period at the department of obstetrics and gynaecology were chosen. Among them, 200 women who fulfilled the inclusion criteria, and opted for repeat caesarean section or had an indication for elective repeat LSCS were included. They were informed about the procedure and a written consent was obtained.

\section{Inclusion criteria}

- Pregnant women with a history of one previous LSCS

- $\quad$ Singleton pregnancy

- Longitudinal lie, cephalic presentation

- Gestational age 36-38 weeks

- Not in labour.

\section{Exclusion criteria}

- Pregnant women with a previous LSCS in active labour

- Pregnant women with previous LSCS with placenta praevia, accreta, increta, percreta

- More than one previous LSCS or any other uterine scar

- Twins and higher order pregnancies

- Polyhydramnios/ oligohydramnios

- Malpresentations.

Women in the study group were seen and evaluated in the antenatal clinic on a regular basis, every 2 weeks until 36 weeks and weekly thereafter. Demographic data, past obstetric history and co-morbidities noted. Details pertaining to previous caesarean section such as indication, gestational age at surgery, operative details (type of caesarean, birth weight), postoperative complications (fever, wound infections, h/o blood transfusions), inter-pregnancy interval were recorded according to a pre-determined proforma.

Inter-pregnancy interval was taken as time period from the previous LSCS to the time of conception in months.

Sonographic assessment of LUS scar thickness was performed for all women between 36-38 weeks of gestation at our hospital by a dedicated radiologist. Philips HD11machine equipped with convex array transducer $(3-5 \mathrm{MHz})$ was used and TAS was done with a partially distended bladder.

On ultrasound, the LUS appeared as a 3 layered structure (Figure 1 and 2): the chorioamnionitic membrane with a decidualized endometrium, the myometrium and the uterovesical peritoneal reflection juxtaposed to muscularis and the mucosa of the bladder.

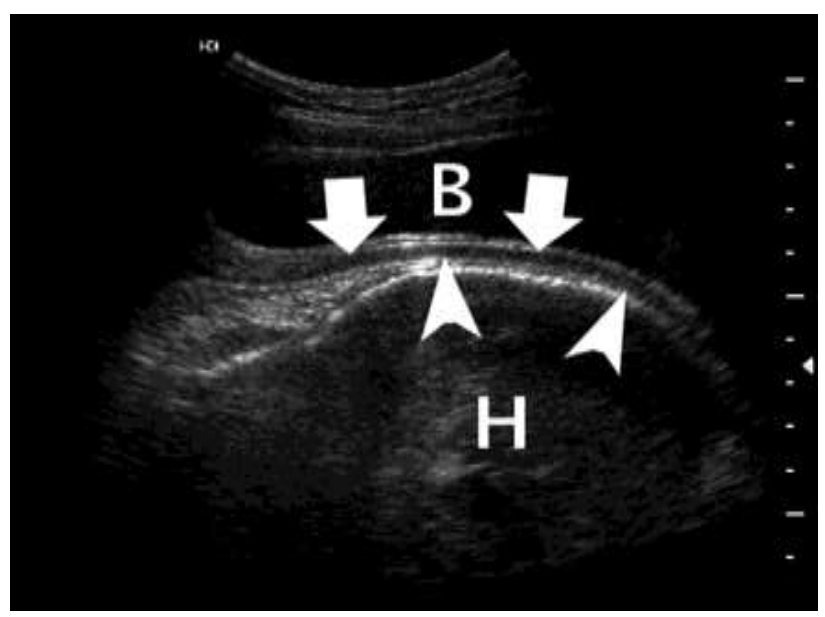

Figure 1: Longitudinal sonogram of the LUS showing the urinary bladder wall-myometrium interface (arrows) and the myometrium/chorioamniotic membrane- amniotic fluid interface (arrowheads). B indicates urinary bladder; and $\mathrm{H}$, fetal head. 
If uterine contraction occurs during USG examination, the procedure was stopped and resumed after the contraction ceased.

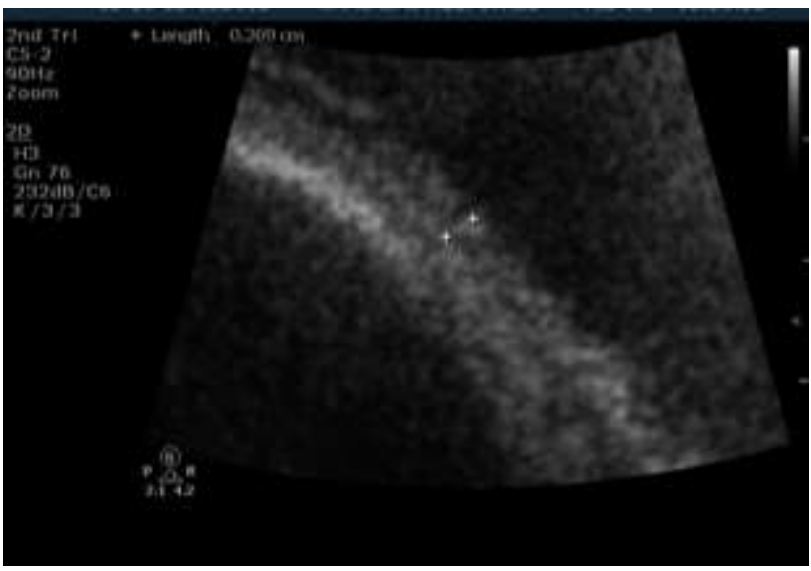

Figure 2: Zoomed in TAS with LUS thickness of $2.69 \mathrm{~mm}$.

LUS was examined longitudinally and transversely to identify any areas of obvious dehiscence or rupture. Lower segment ballooning if any, indicated by abnormal bulging of the outer layer associated with fetal movement or changes in amniotic fluid pressure against the urinary bladder base, was noted. If the LUS appeared intact, an attempt was then made to identify the uterine scar. The thinnest zone of the lower segment was identified in the midsagittal plane along the cervical canal. This area was magnified to the extent that any slight movement of the calliper would produce a change in measurement by only $0.1 \mathrm{~mm}$. The measurement was taken with the cursors at the muscularis and mucosa of bladder (on the outer side) and the chorioamniotic membrane (on the inner side) in sagittal section of the LUS. At least 3 measurements were made, and the lowest value was taken as the LUSscar thickness.

Patients were instructed to report to hospital in the event of any unusual pain during the later weeks of pregnancy or as soon as labour commences. Admission was planned for an elective caesarean at 39 weeks of gestation for all the women after a thorough clinical examination and preoperative evaluation. Operative findings pertaining to birth weight, liquor quantity and scar condition were recorded. LUS was identified as the part of the uterus below the loose reflection of the vesico-uterine serosa. Lower uterine segment was assessed and graded according to the system developed by Qureshi et al. ${ }^{13}$ (Figure 3, 4, 5 and 6).

- Grade I: well developed lower uterine segment.

- Grade II: thin lower segment but the contents are not visible.

- Grade III: translucent (papery thin) lower segment and contents are visible.

- Grade IV: well circumscribed defect, either dehiscence/ rupture
- Grade III and IV were considered as dehiscence groups.

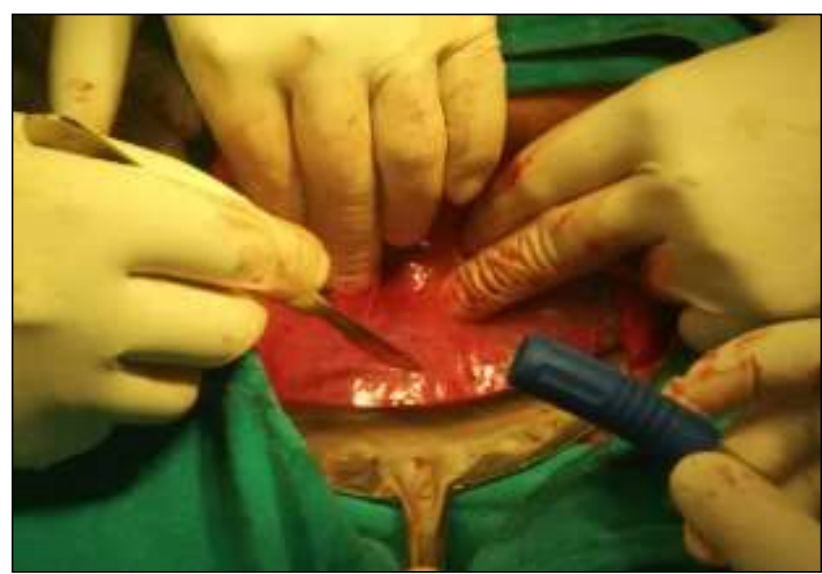

Figure 3: Intraoperative finding of grade I scar in present study.

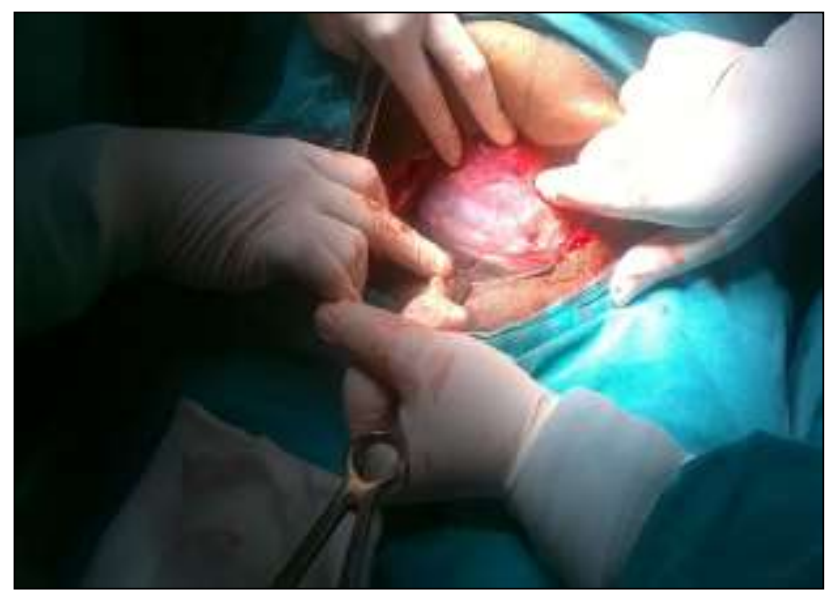

Figure 4: Intraoperative finding of grade II scar in present study.

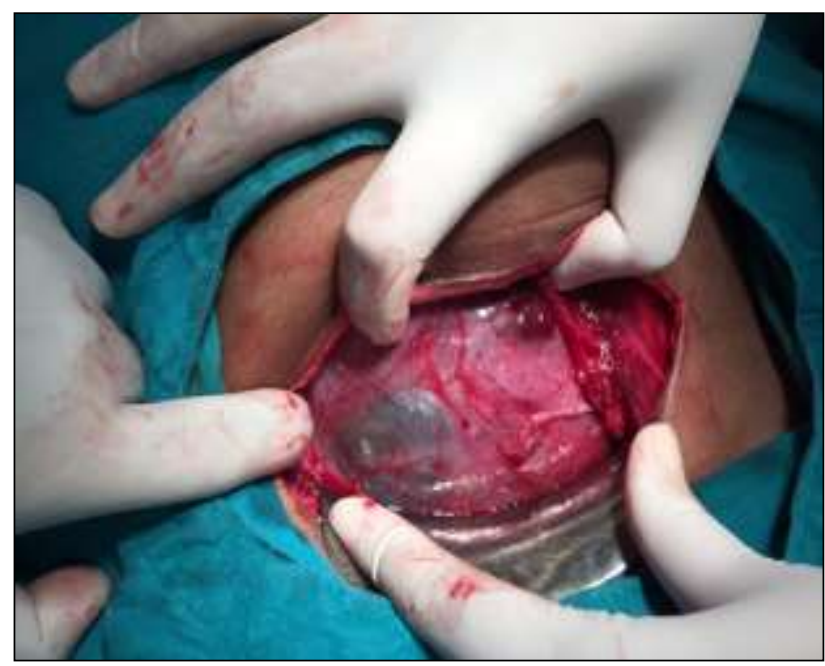

Figure 5: Intraoperative finding of grade III scar in present study. 


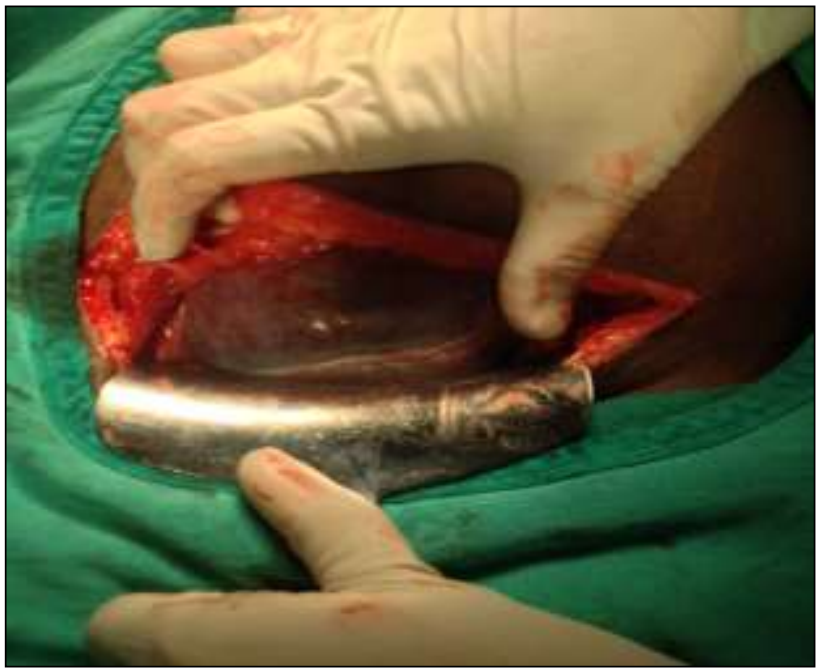

Figure 6: Intraoperative finding of grade IV scar in present study.

Scar dehiscence is defined as separation of muscular layer with an intact serosa.

Scar rupture is defined as separation of all layers of uterine wall with or without expulsion of fetus.

Intraoperative scar grading was then correlated with antenatal ultrasound uterine scar thickness along with the analysis of independent risk factors from obstetrical profile of the women in the dehiscence group. New-born assessment was done by the neonatologist attending the delivery.

\section{Statistical analysis}

Data was expressed as the mean \pm standard deviation (Mean \pm SD). The numbers and percentages (cross tabulations) were computed for categorical data and with appropriate graphs such as bar and pie charts. The unpaired Student t-test and chi-square $\left(\chi^{2}\right)$ were used to compare between groups. The statistical test was done at $5 \%$ level of significance and $\mathrm{p}$ values for appropriate statistical methods. The receiver operating characteristic (ROC) curve was used to find the upper limit and cut-off value for various measurements of LUS.

\section{RESULTS}

Age group of women in the study ranged from 19-39 years. The mean age of the subjects was $26.3 \pm 3.98$ years. Of the total 200 , most women $(n=163)$ were in age group 21-30 years. Table 1 shows the age distribution of subjects.

Mean LUS thickness in the study group was $3.41 \pm 0.623$ $\mathrm{mm}$. Women with a scar thickness of 2.6-3.5 mm formed the largest group $(59.5 \%, \mathrm{n}=119)$ as shown in Table 2 .
Table 1: Distribution of the study group based on age.

\begin{tabular}{|ll|}
\hline Age (years) & Number of subjects \\
\hline$\leq 20$ & 4 \\
\hline $21-25$ & 95 \\
\hline $26-30$ & 68 \\
\hline $31-35$ & 28 \\
\hline$>35$ & 5 \\
\hline Total & $\mathbf{2 0 0}$ \\
\hline
\end{tabular}

Table 2: Distribution of subjects based on USG LUS thickness.

\begin{tabular}{|lll|}
\hline $\begin{array}{l}\text { TAS LUS thickness } \\
(\mathrm{mm})\end{array}$ & $\begin{array}{l}\text { Number of } \\
\text { patients }\end{array}$ & $\%$ \\
\hline $1.6-2.5$ & 13 & 6.5 \\
\hline $2.6-3.5$ & 119 & 59.5 \\
\hline $3.6-4.5$ & 64 & 32.0 \\
\hline$>4.5$ & 4 & 2.0 \\
\hline Total & $\mathbf{2 0 0}$ & $\mathbf{1 0 0 . 0}$ \\
\hline
\end{tabular}

There was a significant distribution in USG category, and it's Chi-Square value was 64.3 with 3 degrees of freedom and P-value 0.0001 .

Table 3 shows distribution of women according to intraop scar gradings. Grade I lower segment was seen in 99 women, Grade II in 74, Grade III in 18 and Grade IV in 9 women.

Table 3: Distribution of subjects based on intraoperative LUS grading.

\begin{tabular}{|lll|}
\hline LUS Grading & No. of patients & $\%$ \\
\hline Grade I & 99 & 49.5 \\
\hline Grade II & 74 & 37.0 \\
\hline Grade III & 18 & 9.0 \\
\hline Grade IV & 09 & 4.5 \\
\hline Total & $\mathbf{2 0 0}$ & $\mathbf{1 0 0 . 0}$ \\
\hline
\end{tabular}

Table 4 and 5 represent cross tabulation and correlation of USG scar thickness with intra-op scar grading as mentioned below -

- Grades I and II were considered non -dehiscence group and grades III and IV were considered dehiscence group.

- Twenty-seven subjects out of $200 \quad(13.5 \%)$ contributed to the scar dehiscence group (grades III $+\mathrm{IV})$.

- Nine subjects out of 200 (4.5\%) had a grade IV intraoperative LUS.

- Six subjects out of $13(46 \%)$ with USG LUS thickness of $</=2.5 \mathrm{~mm}$ had scar dehiscence (grades III+ IV).

- Twenty subjects out of 119 (16.8\%) with USG LUS thickness of $2.6 \mathrm{~mm}-3.5 \mathrm{~mm}$ had scar dehiscence $($ grade III + grade IV). 
- Twenty-six subjects out of $132(19.6 \%)$ with USG LUS thickness of $<3.5 \mathrm{~mm}$ had scar dehiscence (grade III + grade IV)
- $\quad$ One out of $68(1.47 \%)$ with a thickness $>3.5 \mathrm{~mm}$ had dehiscence (grade III).

Table 4: Cross tabulation of USG LUS scar thickness and intraoperative LUS grading.

\begin{tabular}{|c|c|c|c|c|c|}
\hline USG & \multicolumn{4}{|c|}{ Intra-operative LUS } & \multirow{2}{*}{ Total } \\
\hline LUS scar thickness (mm) & Grade I & Grade II & Grade III & Grade IV & \\
\hline $1.6-2.5$ & 1 & 6 & 4 & 2 & 13 \\
\hline $2.6-3.5$ & 44 & 55 & 13 & 7 & 119 \\
\hline $3.6-4.5$ & 51 & 12 & 1 & 0 & 64 \\
\hline$>4.5$ & 3 & 1 & 0 & 0 & 4 \\
\hline Total & 99 & 74 & 18 & 9 & 200 \\
\hline
\end{tabular}

Table 5: Correlation between scar dehiscence and LUS thickness.

\begin{tabular}{|llll|}
\hline Integrity of the scar & $\begin{array}{l}\text { LUS thickness }</=2.5 \\
\text { mm }\end{array}$ & $\begin{array}{l}\text { LUS thickness } 2.6-3.5 \\
\text { mm }\end{array}$ & $\begin{array}{l}\text { LUS thickness }>3.5 \\
\text { mmm }\end{array}$ \\
\hline Intact scar & $7(53.8 \%)$ & $99(83.1 \%)$ & $67(98.5 \%)$ \\
\hline Scar dehiscence & $6(46.1 \%)$ & $20(16.8 \%)$ & $1(1.47 \%)$ \\
\hline Total & $\mathbf{1 3 ( 1 0 0 \% )}$ & $\mathbf{1 1 9}(\mathbf{1 0 0 \%})$ & $\mathbf{6 8}(\mathbf{1 0 0 \%})$ \\
\hline
\end{tabular}

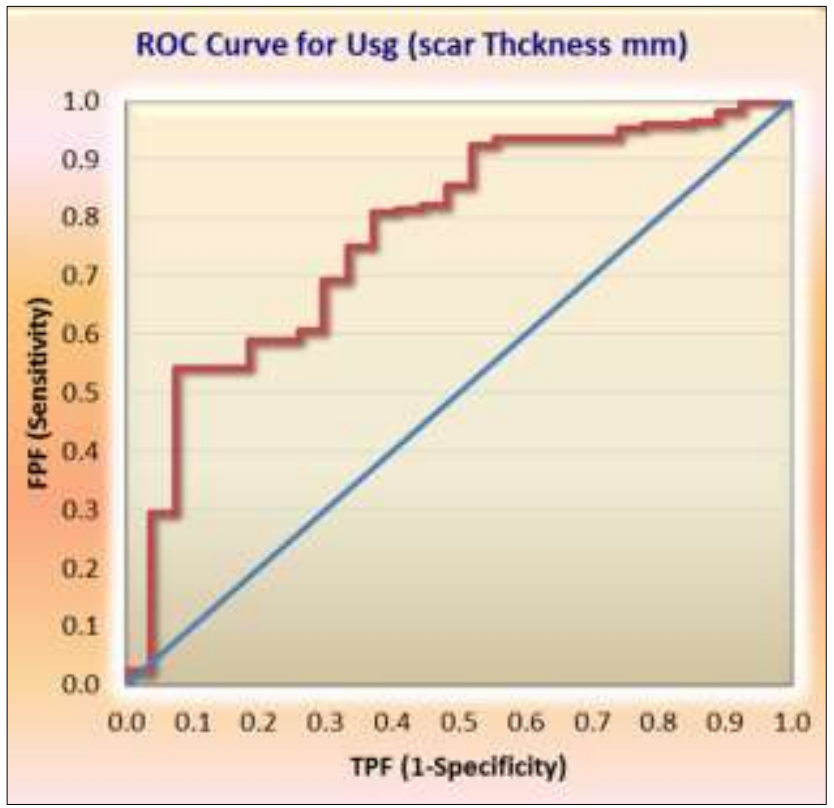

Figure 1: Receiver operating characteristic curve for various cut-off points for scar thickness.

Sonographic measurements of LUS thickness were compared between dehiscence and non-dehiscence groups. The mean LUS thickness in the dehiscence group was $2.98 \pm 0.55 \mathrm{~mm}$, and $3.48 \pm 0.60 \mathrm{~mm}$ in the nondehiscence group, the difference being statistically significant $(\mathrm{p}<=0.001)$. Sensitivity and specificity were calculated at $0.1 \mathrm{~mm}$ intervals of LUS thickness starting at $2 \mathrm{~mm}$ (Figure 7). At a cut-off value of $3.5 \mathrm{~mm}$, the sensitivity, specificity, positive predictive value and negative predictive values were $92.6 \%, 54.3 \%, 24.0 \%$, $97.8 \%$, respectively.

\section{DISCUSSION}

Despite trials of labour after caesarean birth being an accepted practice, the rate of vaginal births after caesarean delivery (VBAC), as well as the rate of attempted TOLAC has decreased during the past 10 years. Patients who fail a trial of labour are at an increased risk of infection and morbidity. Rupture of the uterine scar can be life threatening for both mother and foetus. In most cases, the cause of uterine rupture in a patient who has undergone TOLAC is unknown. Uterine dehiscence can be asymptomatic, not immediately lifethreatening and may exist prior to the onset of labour. ${ }^{14}$ In the present study, uterine scar dehiscence was found among $13.5 \%$ of women at the time of repeat caesarean section prior to the onset of labour. Therefore, measurement of the LUS thickness prior to the onset of labour may have clinical significance if dehiscence can be identified. USG, as an imaging modality for the evaluation of LUS is being increasingly used in current day practice. A number of reports of sonographic evaluation of LUS have appeared in literature since 1982. ${ }^{15-17}$ Rozenberg et al conducted a study using TAS of LUS at 36 to 38 weeks of gestation, included bladder mucosa and peritoneal layer in measurement and deduced a cut off value of $3.5 \mathrm{~mm}$ with a sensitivity of $88.0 \%$, specificity $73.2 \%$, positive predictive value $11.8 \%$ and a negative predictive value $99.3 \%$ suggesting that all thin scars are not abnormal. ${ }^{11}$ 
In the present study, a LUS thickness cut off value of 3.5 mm demonstrated a high NPV $(97.97 \%)$ confirming that a thick LUS may permit conduct of safe vaginal delivery provided all other criteria for TOLAC are fulfilled. ROC curve s were constructed using the scar thickness in the third trimester and the sensitivity and specificity with a range of cut-offs was determined. Regarding the critical thickness, this study had a high NPV, implying that a thick LUS is generally strong. However, the converse may not be true i.e. all thin LUS are dehiscent. This suggests that the USG scar thickness can be used as a screening test for scar dehiscence and women with compromised LUS thickness need to be evaluated further Sen et al used a cut-off value of $2.5 \mathrm{~mm}$ and reported sensitivity, specificity, positive and negative predictive values as follows: $90.9 \%, 84 \%, 71.4 \%$ and $95.5 \%$ (using abdominal sonography) and $81.8 \%, 84 \%, 69.2 \%$ and $91.3 \%$ (using vaginal sonography). ${ }^{18}$ The present study showed an inverse correlation between USG scar thickness and intraoperative scar grading similar to the study by Sen et al. ${ }^{18}$ Others chose $1.5 \mathrm{~mm}$ as the best cutoff value and it yielded a sensitivity of $88.9 \%$, a specificity of $59.5 \%$, a positive predictive value of $32.0 \%$, and a negative predictive value of $96.2 \%$ in predicting a paper-thin or dehiscent LUS. ${ }^{12}$ The authors hence suggested that, as the cut off value of LUS scar thickness is decreased, specificity and PPV are increased however, the sensitivity and NPV decrease.

Most studies have shown a significant relationship between USG LUS scar thickness and intra-operative scar grading. ${ }^{19}$ Lack of standardization of the procedure for measuring lower segment / myometrial thickness led to different cut-off values. Different studies had different

results and the cut-offs varied from as low as $1.5 \mathrm{~mm}$ to as high as $4 \mathrm{~mm}$.

Limitations of this study were as follow;

- Absence of previous operative records in most of the subjects in the study. Information thus obtained may have an additional bearing on scar integrity.

- No trial of labour was done in this study, which is the actual test for the scar.

- Intraoperative quantitative measurement of lower segment with callipers was not done

- which may have given more objective information.

- TVS was not performed.

- Absence of blinding in the study with a chance of intra and inter observer bias.

\section{CONCLUSION}

Ultra-sonographic evaluation of LUS thickness correlated significantly with intraoperative LUS appearance. USG evaluation of LUS can be used as a screening test to predict the LUS scar integrity. Risk of dehiscence is increased in women with thin LUS i.e. sonographic LUS thickness of $<3.5 \mathrm{~mm}$ and needs to be further evaluated.
Women with previous one LSCS with thick LUS i.e. sonographic LUS thickness of > $3.5 \mathrm{~mm}$, can be counselled regarding TOLAC if not contraindicated.

\section{Recommendations}

- Antenatal surveillance for uterine scar integrity should be routinely done for the management of women with a previous caesarean.

- Sonographic screening for LUS thickness may be used to plan the mode of delivery. A $3.5 \mathrm{~mm}$ cut-off is recommended.

- TOLAC can be discussed with pregnant women with a thick LUS/ myometrium and no other comorbidities.

- Discussion regarding the optimum inter-pregnancy interval to be taken up preconceptionally for all women who have undergone Caesarean delivery, keeping in mind the risk of scar dehiscence and rupture in a subsequent pregnancy with a reduced interval.

Funding: No funding sources

Conflict of interest: None declared

Ethical approval: The study was approved by the Institutional Ethics Committee

\section{REFERENCES}

1. Gibbons L, Belizán JM, Lauer JA, Betrán AP, Merialdi M, Althabe F. The global numbers and costs of additionally needed and unnecessary caesarean sections performed per year: overuse as a barrier to universal coverage. World Health Report. 2010:30.

2. World Health Organization. Statement on caesarean section rates, 2015. Available at http://www.who.int/reproductivehealth /publications/ maternal_perinatal_health/cs-statement/en/.

3. Choudhury CR. Caesarean births: The Indian Scenario. Population Association of America; 2008:1-18.

4. Shanti S. Rising rate of caesarean section - a year review. J Nobel Med College. 2012;1:2.

5. Haider G, Zehra N, Munir AA, Haider A. Frequency and indications of cesarean section in atertiary care hospital. Pak J Med Sci. 2009;25(5):791-6.

6. Mozurkewich EL, Hulton EK. Elective repeat cesarean delivery versus trial of labor: a metaanalysis of the literature from 1989 to 1999 . Am J Obstet Gynecol. 2000;183:187-97.

7. ACOG Practice bulletin no. 115: Vaginal birth after previous cesarean delivery. Obstet Gynecol. 2010;116(2Pt 1):450-63.

8. Zelop CM, Shipp TD, Repke JT, Cohen A, Caughey $\mathrm{AB}$, Lieberman E. Uterine rupture during induced or augmented labor in gravid women with one prior caesarean delivery. Am J. Obstet Gynecol. 1999;181:882-6. 
9. Fukuda M, Fukuda K, Mochizuki M. Examination of previous caesarean section scars by ultrasound. Arch Gynecol Obstet. 1988;243:221-4.

10. Rozenberg P, Goffinet F, Phillippe HJ, Nisand I. Ultrasonographic measurement of lower uterine segment to assess risk of defects of scarred uterus. Lancet. 1996;347:281-4.

11. Rozenberg P, Goffinet F, Philippe HJ, Nisand I. Thickness of the lower uterine segment: its influence in the management of patients with previous caesarean sections. Eur J Obstet Gynecol Reprod Biol. 1999;87:39-45.

12. Cheung VY. Sonographic measurement of the lower uterine segment thickness in women with previous caesarean section. J Obstet Gynaecol Can. 2005;27:674-81.

13. Qureshi B, Inafuku K, Oshima K, Masamoto H and Kanazawa K. Ultrasonographic evaluation of lower uterine segment to predict the integrity and quality of cesarean scar during pregnancy: A prospective study. Tohoku J Exp Med. 1997;183(1):55-65.

14. Hirobumi A, Akihito N, Gen I, Shyunji S, Tsotumu A. Prediction of uterine dehiscence by measuring lower uterine segment thickness prior to the onset of labor. J Nippon Med Sch. 2000;67(5):352-8.

15. Araki $T$, Inooka $H$. The diagnostic value of ultrasonotomography with reference to previous cesarean section scars during full term pregnancy. Acta Obstet Gynecol Scand. 1982; 34: 738-44.
16. Jastrow N, Chaillet N, Roberge S, Morency AM, Lacasse Y, Bujold E. Sonographic lower uterine segment thickness and risk of uterine scar defect: a systematic review. J ObstetGynaecol Can 2010; 4: 321-7.

17. Kushtagi P, Garepalli S. Sonographic assessment of lower uterine segment at term in women with previous cesarean delivery. Arch Gynecol Obstet. 2011;283(3):455-9.

18. Sen S, Malik S, Salhan S. Ultrasonographic evaluation of lower uterine segment thickness in patients of previous cesareansection. Int J Gynaecol Obstet. 2004;87(3):215-9.

19. Asakura H, Nakai A, Ishikawa G, Suzuki S, Araki T. Prediction of uterine dehiscence by measuring lower uterine segment thickness prior to the onset of labor: evaluation by transvaginal ultrasonography. J Nippon Med Sch. 2000;67(5):352-6.

Cite this article as: Vedantham H, Jahagirdar NJN, Ramadevi N, Kamineni V, Saranu S. A study of correlation of antenatal uterine scar thickness by transabdominal ultrasound with intraoperative lower uterine segment scar grading in elective repeat cesarean delivery. Int J Reprod Contracept Obstet Gynecol 2019;8:4878-84. 